Article

\title{
Particle size effects in Fischer-Tropsch synthesis by Co catalyst supported on carbon nanotubes
}

\author{
Ali Nakhaei Pour*, Elham Hosaini, Mohammad Izadyar, Mohammad Reza Housaindokht \\ Department of Chemistry, Ferdowsi University of Mashhad, P.O. Box: 9177948974, Mashhad, Iran
}

\section{A R T I C L E I N F O}

Article history:

Received 18 February 2015

Accepted 19 March 2015

Published 20 August 2015

\section{Keywords:}

Fischer-Tropsch synthesis

Co catalysts

Carbon nanotubes

Size dependent parameters

Kinetics

\begin{abstract}
A B S T R A C T
The effect of Co particle size on the Fischer-Tropsch synthesis (FTS) activity of carbon nanotube (CNT)-supported Co catalysts was investigated. Microemulsion (using water-to-surfactant molar ratios of 2 to12) and impregnation techniques were used to prepare catalysts with different Co particle sizes. Kinetic studies were performed to understand the effect of Co particle size on catalytic activity. Size-dependent kinetic parameters were developed using a thermodynamic method, to evaluate the structural sensitivity of the CNT-supported Co catalysts. The size-independent FTS reaction rate constant and size-independent adsorption parameter increased with increasing reaction temperature. The Polani parameter also depended on catalyst particle size, because of changes in the catalyst surface coverage.
\end{abstract}

(C) 2015, Dalian Institute of Chemical Physics, Chinese Academy of Sciences. Published by Elsevier B.V. All rights reserved.

\section{Introduction}

Fischer-Tropsch synthesis (FTS) involves producing liquid hydrocarbons from synthesis gas ( $\mathrm{CO}$ and $\mathrm{H}_{2}$ ) via surface polymerization. FTS is a promising alternative for producing clean fuels from non-crude-oil sources [1]. FTS is a polymerization surface reaction, so it is influenced by the type and structure of the catalyst [2-5]. Co and Fe are industrial FTS catalysts used in Qatar and South Africa. Co-based catalysts are usually preferred, because of their higher activity, higher chain growth probability, and lower water-gas shift activity [6].

The supports of Co-based catalysts affect their turnover rate (rate per surface Co site) [3,7]. The catalyst support should provide well-dispersed stable Co particles, after catalyst reduction and activation. Supports can have negative effects, such as forming Co-support compounds like cobalt aluminate and cobalt silicate [8-10], which do not provide active sites for FTS. Carbon nanotubes (CNTs) as Co catalyst supports provide good control over the Co dispersion, while minimizing the formation of mixed compounds $[11,12]$. CNTs as Co catalyst supports provide favorable catalytic activity for FTS. CNT-supported Co catalysts also allow the effect of the Co particle size to be investigated, because of the weak interaction between the support and Co nanoparticles [13].

The size of Co particles in supported Co catalysts may affect their FTS activity. Using metallic nanoparticles in heterogeneous catalysis is well established, with a smaller particle size providing a higher proportion of surface atoms. Surface atoms at edges or corners are also more active than those within planes, and their proportion also increases with decreasing particle size [14-20]. Barbier et al. [14] and Bezemer and co-workers $[13,15]$ reported that the FTS activity and selectivity were sensitive to Co particle size for particles smaller than $10 \mathrm{~nm}$. However, the effect of Co particles smaller than $10 \mathrm{~nm}$ on FTS activity remains controversial, and more research is required. Khodakov [16] reviewed the influence of Co particle size and phase composition on FTS activity. Prieto et al. [17] observed that the FTS activity of silica-supported Co catalysts

\footnotetext{
* Corresponding author. Tel/Fax: +98-5138795457; Email: a.nakhaei@um.ac.ir, nakhaeipoura@yahoo.com 
increased with increasing Co particle size from 5.6 to $10.4 \mathrm{~nm}$, and then remained constant for further increasing particle size up to $141 \mathrm{~nm}$. Wang et al. [18] reported that the minimal effect of the size of 3.5-10.5 nm Co particles was consistent with the insensitivity of their FTS activity.

Reaction rates for nanomaterials of different sizes and shapes can be compared using the thermodynamic method, reported by Parmon [19] and developed by Murzin [20-23]. This method evaluates the effect of nanoparticle size on adsorption and kinetics, by calculating the chemical potential of the active phase (e.g. clusters supported on a carrier) [4,24].

In the current study, CNTs were used as an inert support to study the effect of Co particle size on FTS activity. Five Co/CNT catalysts with Co particle sizes of 4.9-12.4 nm were prepared. Transmission electron microscopy (TEM) and X-ray diffraction (XRD) were used to characterize the particle size distribution. Kinetic and thermodynamic models were established to evaluate the effect of particle size on FTS activity.

\section{Experimental}

\subsection{Preparation}

Catalysts were prepared from $15 \mathrm{wt} \%$ Co on CNT supports by incipient wetness impregnation and microemulsion techniques reported previously [11]. The microemulsion technique involves precipitating in a single-phase region, yielding catalysts containing varying Co particle sizes. The surfactant-to-oil weight ratio was 0.3 , and the water-to-surfactant (W/S) molar ratio was $2-12$.

\subsection{Characterization}

Powder XRD patterns of calcined samples were recorded on a Philips PW1840 diffractometer, using monochromatic $\mathrm{Cu} K_{\alpha}$ radiation. Phases were identified by comparison with the JCPDS database. The average $\mathrm{Co}_{3} \mathrm{O}_{4}$ crystallite size was calculated from the Scherrer equation, using the $\mathrm{Co}_{3} \mathrm{O}_{4}$ peak of the (311) plane at $2 \theta=36.9^{\circ}$ and a $K$ factor of 0.89 . This particle size was converted to the corresponding $\mathrm{Co}^{0}$ particle size, using the relative molar volumes of $\mathrm{Co}^{0}$ and $\mathrm{Co}_{3} \mathrm{O}_{4}$, according to [25]:

$$
d\left(\mathrm{Co}^{0}\right)(\mathrm{nm})=0.75 \times d\left(\mathrm{Co}_{3} \mathrm{O}_{4}\right)
$$

The morphology of the calcined Co nanoparticles was observed by TEM (LEO 912 AB, Germany). An appropriate amount of catalyst suspension was deposited and allowed to dry on a carbon-coated copper grid, and was then observed by TEM.

\subsection{Activity}

Steady-state FTS reaction rates were measured in a continuous spinning basket reactor (stainless steel, height $0.122 \mathrm{~m}$, outer diameter $0.052 \mathrm{~m}$, inner diameter $0.046 \mathrm{~m}$ ), with temperature controllers (WEST series 3800), separated mass flow controllers (Brooks's 5850), and a back pressure valve for controlling the pressure. A detailed description of this setup and procedure have been reported previously [26]. The weight of the loaded catalyst was $2.5 \mathrm{~g}$, which was dispersed in inert silica sand (of the same mesh size) to give a final volume of 30 $\mathrm{cm}^{3}$. This was reduced in situ at $673 \mathrm{~K}$ for $12 \mathrm{~h}$ under a stream of $\mathrm{H}_{2}$, at 1 bar and space velocity of $3.6 \mathrm{Nl} /\left(\mathrm{g}_{\text {cat }} \cdot \mathrm{h}\right)$. Blank experiments showed that the spinning basket reactor charged with inert silica sand containing no catalyst did not convert syngas. After pretreatment, FTS tests were carried out at $493 \mathrm{~K}$, 20 bar, $\mathrm{H}_{2} / \mathrm{CO}$ ratio of 2 , and a space velocity of $2.4 \mathrm{Nl} /\left(\mathrm{g}_{\text {cat }} \cdot \mathrm{h}\right)$. Kinetic measurements were carried out after a $12 \mathrm{~h}$ stabilization period at these conditions.

During runs, the reactor temperature was 493 and $508 \mathrm{~K}$, pressure was $20 \mathrm{bar}$, and the space velocity of the synthesis gas was $2.4 \mathrm{Nl} /\left(\mathrm{g}_{\text {cat }} \cdot \mathrm{h}\right)$. The $\mathrm{H}_{2} / \mathrm{CO}$ ratio of the feed was constant. The products formed from converting $\mathrm{CO}$ and $\mathrm{H}_{2}$ were measured over a 24 -h period. It took at least $4 \mathrm{~h}$ to ensure the steady-state behavior of the catalyst, following a change in reaction conditions.

The products were analyzed by three gas chromatography apparatuses, as reported previously [11,27-29]. CO conversion was calculated based on the GC analyses and carbon balance. The total mass and atomic material balances were measured, and runs were further analyzed if their carbon balance fell within $97 \%$ to $103 \%$. This criterion was adopted since carbon and hydrogen can accumulate in the reactor, in the form of high molecular weight hydrocarbons.

\section{Results and discussion}

\subsection{Catalyst characterization}

Fig. 1 shows TEM images of a calcined CNT support and catalyst prepared by microemulsion, at a W/S of 4 . Table 1 lists the average particle size ( $d_{\text {TEM }}$ ) determined from $>100$ particles using the average Feret diameter, as reported previously [11]. The $d_{\text {TEM }}$ value was a direct measure of the Co nanoparticle size, so was used for further calculations.

XRD patterns of the calcined catalysts are shown in Fig. 2.

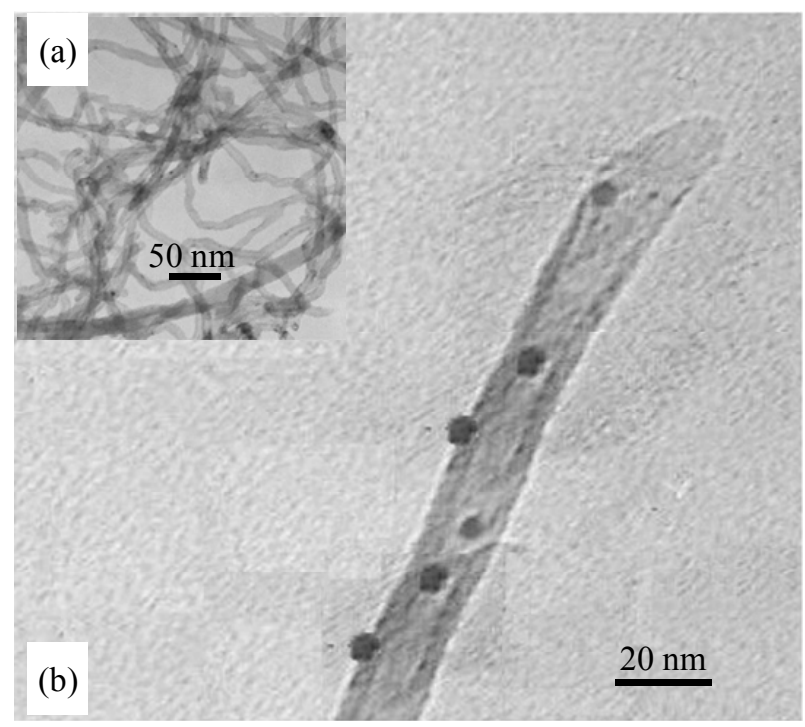

Fig. 1. TEM images of a CNT support (a) and calcined catalyst prepared by the microemulsion technique at a W/S of 4 (b). 
Table 1

Particle sizes of prepared catalysts as observed by TEM and calculated from XRD results.

\begin{tabular}{lccc}
\hline \multirow{2}{*}{ Preparation method } & \multirow{2}{*}{ W/S ratio } & \multicolumn{2}{c}{ Average $\mathrm{Co}^{0}$ particle size $(\mathrm{nm})$} \\
\cline { 3 - 4 } & & XRD & TEM \\
\hline Impregnation & - & 12.1 & 12.4 \\
Microemulsion & 2 & 4.6 & 4.9 \\
Microemulsion & 4 & 7.6 & 7.9 \\
Microemulsion & 8 & 8.3 & 8.6 \\
Microemulsion & 12 & 9.4 & 9.8 \\
\hline
\end{tabular}

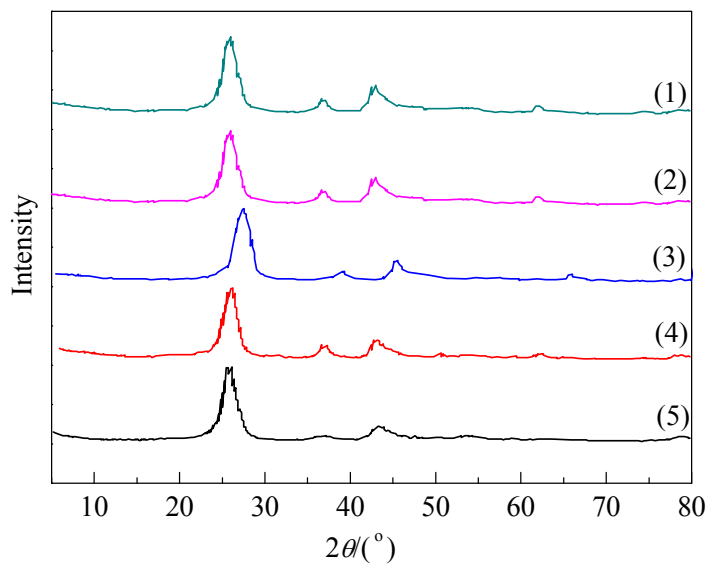

Fig. 2. XRD patterns of calcined catalysts prepared by the impregnation method (1), and by the microemulsion method at a W/S of 12 (2), 8 (3), $4(4)$, and 2 (5).

Diffraction peaks at $25^{\circ}$ and $43^{\circ}$ corresponded to the CNT support, that at $36.8^{\circ}$ to the (311) plane, and those at $44^{\circ}(400)$, $59^{\circ}(511)$ and $65^{\circ}(440)$ to the cubic spinel structure of $\mathrm{Co}_{3} \mathrm{O}_{4}$ (JCPDS 78-1970).

Table 1 lists the average $\mathrm{Co}^{0}$ particle sizes, which were calculated from $\mathrm{Co}_{3} \mathrm{O}_{4}$ crystallite sizes using Eq. (1). Table 1 shows that the average particle sizes depended linearly upon the microemulsion $\mathrm{W} / \mathrm{S}$ ratio. The $d_{\mathrm{XRD}}$ value was an indirect measure of particle size, which reflected cumulative information.

\subsection{FTS activity}

The Co/CNT catalysts allowed the effect of Co particle size on FTS activity to be investigated. The catalytic activity of catalysts at 493 and $508 \mathrm{~K}, 20 \mathrm{bar}, \mathrm{H}_{2} / \mathrm{CO}$ ratio of 2 , and space velocity of synthesis gas of $2.4 \mathrm{Nl} /\left(\mathrm{g}_{\mathrm{cat}} \cdot \mathrm{h}\right.$ ) were examined. The effect of temperature and particle size on FTS reaction rate is shown in Fig. 3. The catalyst particle size $(r)$ corresponded to the $\mathrm{Co}^{0}$ nanoparticle radius, and $r$ FTs was the rate of CO conversion to organic products. Fig. 3 shows that the FTS reaction rate increased with increasing temperature. The FTS reaction rate increased with increasing catalyst particle size until reaching a maximum, and then decreased with further increasing particle size. These results show that the FTS reaction was sensitive to the Co catalyst structure, but did not yield a simple correlation between catalyst activity and particle size.

To understand the effect of particle size on catalytic activity, kinetic studies were performed using the equation developed by Eric van Steen and Hans Schulz [30]:

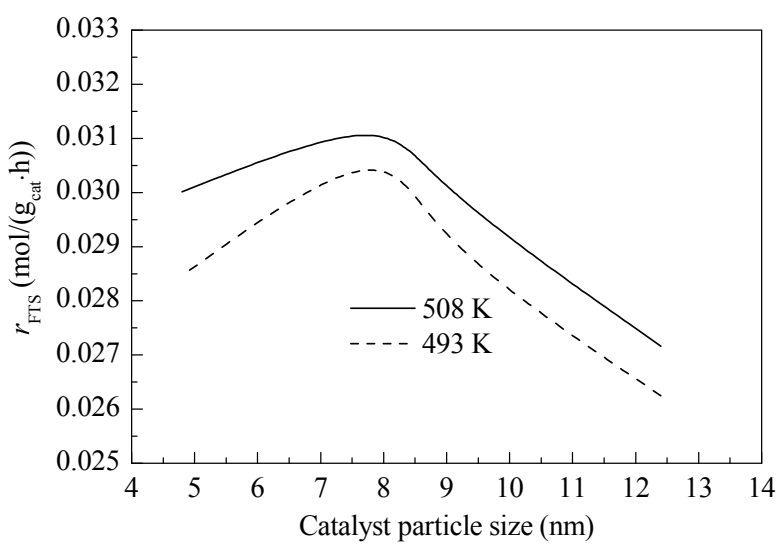

Fig. 3. Effect of temperature and catalyst particle size on FTS reaction rate.

$$
r_{\mathrm{FTS}}=\frac{k_{\mathrm{FTS}} b}{\left[1+b\left(\frac{P_{\mathrm{H}_{2}} P_{\mathrm{CO}}}{P_{\mathrm{H}_{2} \mathrm{O}}}\right)\right]^{2}}\left(\frac{P_{\mathrm{H}_{2}}^{3 / 2} P_{\mathrm{CO}}}{P_{\mathrm{H}_{2} \mathrm{O}}}\right)
$$

The elementary reactions for driving this equation are listed Table 2. Calculated rate constants ( $k_{\mathrm{FTS}}$ ), adsorption parameters (b) at various temperatures, activation energies for FTS reaction $\left(E_{\mathrm{a}}\right)$ and adsorption enthalpies $\left(\Delta H_{\mathrm{ads}}\right)$ for various Co catalysts are listed in Table 3.

Table 3 shows that decreasing the particle size lead to an increase in $k_{\text {FTS }}$ and $b$. These results allowed the effect of Co particle size on FTS activity to be interpreted. Eq. (2) indicates that an increase in $k_{\text {FTS }}$ or decrease in $b$ will increase the rate of the Co/CNT-catalyzed FTS reaction. Fig. 3 shows that decreasing the particle size resulted in the FTS reaction rate passing through a maximum. Before this maximum rate, the $k_{\text {FTs }}$ was dominant, and the FTS reaction rate increased with increasing $k$ FTs. After this maximum rate, $b$ was dominant, and the FTS

Table 2

Elementary reactions for the model proposed in Ref. [30].

\begin{tabular}{lcc}
\hline Reaction step & Equilibrium Constant & Elementary reaction \\
\hline 1 & $K_{1}$ & $\mathrm{H}_{2}+2 \mathrm{~s}=2 \mathrm{Hs}$ \\
2 & $K_{2}$ & $\mathrm{CO}+\mathrm{s}=\mathrm{COs}$ \\
3 & $K_{3}$ & $\mathrm{COs}+\mathrm{s}=\mathrm{Cs}+\mathrm{Os}$ \\
4 & $K_{4}$ & $\mathrm{Os}+2 \mathrm{Hs}=\mathrm{H}_{2} \mathrm{O}+3 \mathrm{~s}$ \\
5 & $k_{\mathrm{FTs}}$ & $\mathrm{Cs}+\mathrm{Hs} \rightarrow \mathrm{CHs}+\mathrm{s}$ \\
\hline
\end{tabular}

\section{Table 3}

Rate constants $(k)$, adsorption parameters $(b)$, activation energies $\left(E_{\mathrm{a}}\right)$ and adsorption enthalpies ( $\Delta H_{\text {ads }}$ ) for Co catalysts at 493 and $508 \mathrm{~K}$, calculated according to Ref. [30].

\begin{tabular}{lccccc}
\hline $\begin{array}{l}\text { Co particle } \\
\text { size }(\mathrm{nm})\end{array}$ & $\begin{array}{c}T \\
(\mathrm{~K})\end{array}$ & $\begin{array}{c}k_{\mathrm{FTS}} \\
\left(\mathrm{mol} \cdot \mathrm{g} \cdot \mathrm{h}^{-1} \cdot \mathrm{bar}^{-3 / 2}\right)\end{array}$ & $\begin{array}{c}b \\
\left(\mathrm{bar}^{-2}\right)\end{array}$ & $\begin{array}{c}E_{\mathrm{a}} \\
(\mathrm{kJ} / \mathrm{mol})\end{array}$ & $\begin{array}{c}-\Delta H_{\text {ads }} \\
(\mathrm{kJ} / \mathrm{mol})\end{array}$ \\
\hline 12.4 & 493 & 0.052 & 0.019 & 98 & 63 \\
& 508 & 0.105 & 0.030 & & \\
9.8 & 493 & 0.060 & 0.045 & 96 & 67 \\
& 508 & 0.121 & 0.073 & & \\
8.6 & 493 & 0.070 & 0.074 & 94 & 69 \\
7.9 & 508 & 0.142 & 0.122 & & \\
& 493 & 0.081 & 0.111 & 91 & 71 \\
4.8 & 508 & 0.156 & 0.186 & & 74 \\
\hline
\end{tabular}


reaction rate decreased with increasing $b$. This analysis was based on the Sabatier principle, which states that the interaction between catalyst and substrate should be neither too strong nor too weak $[32,33]$.

\subsection{Size dependent kinetic parameters}

FTS reaction rates were analyzed above in terms of $k_{\text {FTS }}$ and $b$. However, why $k_{\text {FTS }}$ and $b$ increased with decreasing catalyst particle size was not of current concern. These relationships were considered using the kinetic-thermodynamic method developed by Murzin and Parmon, for evaluating the structural sensitivity of heterogeneous catalysts [19-23]. The Gibbs free energy is related to the catalyst particle size by:

$$
\Delta G_{\text {ads }}(r)=\Delta G_{\text {ads }, \infty}+\mu_{\mathrm{i}}(r)-\mu_{\infty}=\Delta G_{\text {ads }, \infty} \pm \frac{2 \sigma V_{\mathrm{M}}}{r}=\Delta G_{\text {ads }, \infty} \pm \delta(r)
$$

where $r$ is the catalyst active site dimension, $V_{\mathrm{M}}$ is the partial molar volume of the condensed phase, $\sigma$ is the surface tension, and the parameter $\delta(r)=2 \sigma V_{\mathrm{M}} / r$. Depending on the nature of the bonding between molecule and nanoparticle surface, the change in adsorption free energy from the nanosize effect can be positive or negative. The thermodynamic adsorption constant $\left(K_{\mathrm{ads}}\right)$ can be expressed in the size-dependent equation:

$$
\begin{gathered}
\Delta G_{\text {ads }}(r)=-\mathrm{R} T \ln K_{\text {ads }}(r)=\Delta G_{\text {ads }, \infty} \pm \frac{2 \sigma V_{\mathrm{M}}}{r}=-\mathrm{R} T \ln K_{\text {ads } \infty} \pm \frac{2 \sigma V_{\mathrm{M}}}{r} \\
K_{\text {ads }}(r)=K_{\text {ads } \infty} \exp \left(\mp \frac{2 \sigma V_{\mathrm{M}}}{r \mathrm{R} T}\right)=K_{\text {ads } \infty} \exp \left(\mp \frac{\eta}{r}\right)
\end{gathered}
$$

where $K_{\mathrm{adss}}$ is the size-independent part of $K_{\mathrm{ads}}$, the parameter $\eta=2 \sigma V_{\mathrm{M}} / \mathrm{R} T$, R is the universal gas constant, and $T$ is temperate in K. Eq. (3) shows that the Gibbs free energy for the elementary steps in Table 2 can be written as:

$$
\begin{aligned}
& \Delta G_{1}=\Delta G_{1 \infty}-2 \delta(r) \\
& \Delta G_{2}=\Delta G_{2 \infty}-\delta(r) \\
& \Delta G_{3}=\Delta G_{3 \infty}-2 \delta(r) \\
& \Delta G_{4}=\Delta G_{4 \infty}+3 \delta(r) \\
& \Delta G_{5}=\Delta G_{5 \infty}+2 \delta(r)
\end{aligned}
$$

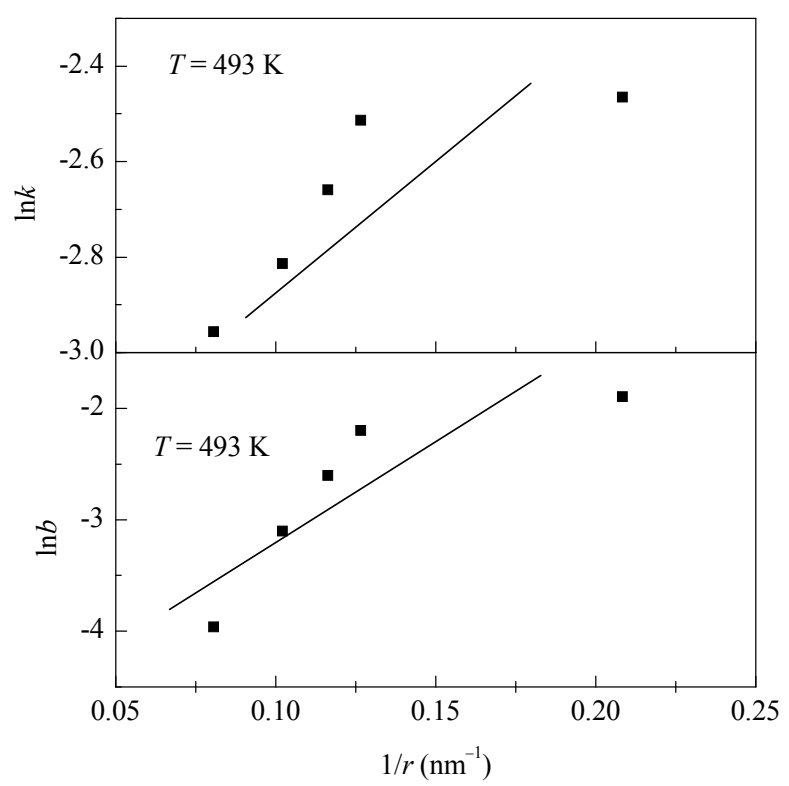

The total Gibbs free energy $\Delta G_{T}=\Delta G_{1}+\Delta G_{2}+\Delta G_{3}+\Delta G_{4}+$ $\Delta G_{5}$ is independent of catalyst particle size. From Eq. (5):

$$
\begin{aligned}
& K_{1}=K_{1 \infty} \exp \left(\frac{2 \eta}{r}\right) \\
& K_{2}=K_{2 \infty} \exp \left(\frac{\eta}{r}\right) \\
& K_{3}=K_{3 \infty} \exp \left(\frac{2 \eta}{r}\right) \\
& K_{4}=K_{4 \infty} \exp \left(-\frac{3 \eta}{r}\right)
\end{aligned}
$$

So the expression of $b=K_{1}^{2} K_{2} K_{3} K_{4}$ becomes:

$$
b=K_{1}^{2} K_{2} K_{3} K_{4}=b_{\infty} \exp \left(\frac{4 \eta}{r}\right)
$$

where $b_{\infty}=K_{1} \infty^{2} K_{2} \infty K_{3} \infty K_{4} \infty$. The relationship between $k$ and $K$ is given by the Brønsted-Polanyi relationship $k=g K x$, where $g$ and $\chi$ are the Brønsted-Polanyi parameters, and $0<\chi<1$. For the $k_{\mathrm{FTS}}\left(\Delta G_{5}=\Delta G_{500}+2 \delta(r)\right)$ based on the elementary steps in Table $2[4,21-24,34]$ :

$$
k_{\mathrm{FTS}}=\mathrm{g} K^{2(1-\chi)}=k_{\mathrm{FTS} \infty} \exp \left(\frac{2(1-\chi) \eta}{r}\right)
$$

Equations (6) and (7) can be used to evaluate the size-dependent parameters from the experimental results. To evaluate the thermodynamic size-dependence parameters, the size-dependent FTS rate constant and adsorption parameter (b) (Eqs. (6) and (7)) are linearized by rearrangement as:

$$
\begin{gathered}
\ln b=\ln b_{\infty}+\frac{4 \eta}{r} \\
\ln k_{\mathrm{FTS}}=\ln k_{\mathrm{FTS} \infty}+\frac{2(1-\chi) \eta}{r}
\end{gathered}
$$

Plots of $\ln \left(k_{\mathrm{FTS}}\right)$ and $\ln (b)$ versus $1 / r$ should yield straight lines, with intercepts of $\ln \left(k_{\mathrm{FTS} \infty}\right)$ and $\ln \left(b_{\infty}\right)$ and gradients of $2(1-\chi) \eta$ and $4 \eta$, respectively. Fig. 4 shows the linear plots of Eqs. (8) and (9) for the various Co/CNT catalysts. The Polanyi parameter $(\chi)$ was taken to $\sim 0.5$ in fitting, which is typical for this parameter [21-23]. The calculated thermodynamic-size

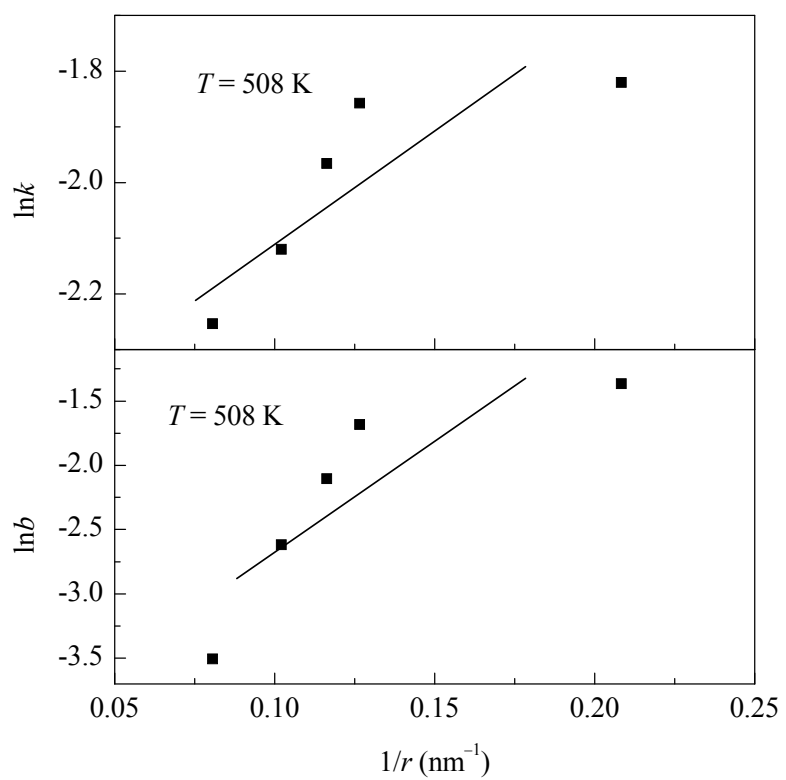

Fig. 4. Linearized plots of Eqs. 8 and 9 for various Co/CNT catalysts. 
Table 4

Size-dependent FTS kinetic parameters.

\begin{tabular}{lcccc}
\hline$T(\mathrm{~K})$ & $\eta(\mathrm{nm})$ & $\chi$ & $\begin{array}{c}k_{\mathrm{FTS}} \\
\left(\mathrm{mol} \cdot \mathrm{g}_{\mathrm{cat}}{ }^{-1} \cdot \mathrm{h}^{-1} \cdot \mathrm{bar}^{-3 / 2}\right)\end{array}$ & $\begin{array}{c}b_{\infty} \\
\left(\mathrm{bar}^{-2}\right)\end{array}$ \\
\hline 493 & 3.51 & 0.5 & 0.044 & 0.011 \\
508 & 3.05 & 0.5 & 0.092 & 0.017 \\
\hline
\end{tabular}

dependent parameters are listed in Table 4. The size-independent FTS reaction rate constant $\left(k_{\infty}\right)$ and size-independent adsorption parameter $\left(b_{\infty}\right)$ increased, and the $\eta$ parameter decreased, with increasing reaction temperature.

Table 3 shows that the $E_{\mathrm{a}}$ of the catalysts increased from 89 to $98 \mathrm{~kJ} / \mathrm{mol}$, and the $\Delta H_{\text {ads }}$ decreased from 74 to $63 \mathrm{~kJ} / \mathrm{mol}$, as $r$ increased from 4.8 to $12.4 \mathrm{~nm}$. The Sabatier principle states that the reactivity of surface reactions (i.e. $E_{\mathrm{a}}$ ) and $\Delta H_{\text {ads }}$ exhibit opposing behavior. Thus, the behavior of the catalyst with particle size in Fig. 4 can be accounted for by the Sabatier principle. Eqs. (10) and (11) imply that the $\Delta H$ and $E_{\mathrm{a}}$ of the overall catalytic process depend on $r$, according to [19]:

$$
\begin{aligned}
& -\Delta H(r)=-\Delta H_{\infty}+\frac{4 \eta}{r} \mathrm{R} T \\
& E_{\mathrm{a}}(r)=E_{\infty}-\frac{2(1-\chi) \eta}{r} \mathrm{R} T
\end{aligned}
$$

where $E_{\infty}$ is the size-independent activation energy and $\Delta \mathrm{H}_{\infty}$ is the size-independent adsorption enthalpy. These parameters were calculated by extrapolating plots of size-dependent activation energies and size-dependent adsorption enthalpies against $1 / r$ in Fig. 4 to value of $0(r=\infty)$. Table 5 lists the $E_{\infty}$, $\Delta H_{\infty}, k_{\mathrm{FTS}}$ values calculated using Eq. $7, b$ calculated using Eq. (6), Ea calculated using Eq. (10), and apparent heats of adsorption of catalysts calculated using Eq. (11). Comparing the results in Table 5 with those in Table 3 shows that the calculated activation energy and adsorption enthalpy did not agree with the experimental results.

\subsection{Size dependent kinetic study}

The size-dependent kinetic parameters obtained from Eqs. (6) and (7) were substituted into Eq. (2), to obtain a size-dependent kinetic equation for the FTS activity of the Co/CNT catalysts :

$$
r_{\mathrm{FTS}}=\frac{k_{\mathrm{FTS} \infty} b_{\infty}}{\left[1+b_{\infty} \exp \left(\frac{4 \eta}{r}\right)\left(\frac{P_{\mathrm{H}_{2}} P_{\mathrm{CO}}}{P_{\mathrm{H}_{2} \mathrm{O}}}\right)\right]^{2}} \exp \left(\frac{3(2-\chi) \eta}{r}\right)\left(\frac{P_{\mathrm{H}_{2}}^{3 / 2} P_{\mathrm{CO}}}{P_{\mathrm{H}_{2} \mathrm{O}}}\right)
$$

Table 6

Effect of temperature and catalyst particle size on FTS reaction rate $\left(r_{\mathrm{FTS}}\right)$.

\begin{tabular}{lrccrc}
\hline $\begin{array}{l}T \\
(\mathrm{~K})\end{array}$ & $\begin{array}{c}d_{\text {cat. }} \\
(\mathrm{nm})\end{array}$ & $P_{\mathrm{H} 2}(\mathrm{bar})$ & $\begin{array}{c}P_{\mathrm{c} 0} \\
(\mathrm{bar})\end{array}$ & $\begin{array}{c}P_{\mathrm{H} 20} \\
(\mathrm{bar})\end{array}$ & $\begin{array}{c}r_{\mathrm{FTS}} \\
{[\mathrm{mol} /(\mathrm{gcat} \cdot \mathrm{h})]}\end{array}$ \\
\hline 493 & 12.4 & 7.8 & 2.6 & 7.8 & 0.0263 \\
& 9.8 & 6.9 & 2.1 & 8.7 & 0.0283 \\
& 8.6 & 6.3 & 1.7 & 9.3 & 0.0297 \\
& 7.9 & 5.7 & 1.3 & 9.9 & 0.0310 \\
508 & 4.8 & 6.4 & 2.0 & 8.7 & 0.0285 \\
& 12.4 & 7.2 & 2.3 & 8.0 & 0.0272 \\
& 9.8 & 6.2 & 1.7 & 9.1 & 0.0293 \\
& 8.6 & 5.7 & 1.3 & 9.6 & 0.0305 \\
& 7.9 & 5.1 & 1.0 & 10.0 & 0.0314 \\
& 4.8 & 5.8 & 1.5 & 9.2 & 0.0300 \\
\hline
\end{tabular}

Reaction conditions: total pressure $=20 \mathrm{bar}, \mathrm{GHSV}=2.4 \mathrm{Nl} /\left(\mathrm{g}_{\text {cat }} \cdot \mathrm{h}\right)$, feed $\mathrm{H}_{2} / \mathrm{CO}$ molar ratio $=2$.

\section{Table 7}

Calculated rate constants $\left(k_{\mathrm{FTS}}\right)$ and adsorption parameters $(b)$ for Co catalysts at 493 and $508 \mathrm{~K}$, after improving their size-dependent parameters.

\begin{tabular}{lccccc}
\hline$d_{\text {cat }}(\mathrm{nm})$ & $\begin{array}{c}T \\
(\mathrm{~K})\end{array}$ & $\chi$ & $a$ & $\begin{array}{c}k_{\mathrm{FTS}} \\
\left(\mathrm{mol}_{\mathrm{cat}}{ }^{-1} \cdot \mathrm{h}^{-1} \cdot \mathrm{bar}^{-3 / 2}\right)\end{array}$ & $\begin{array}{c}b \\
\left(\mathrm{bar}^{-2}\right)\end{array}$ \\
\hline \multirow{2}{*}{12.4} & 493 & 0.70 & 2.0 & 0.052 & 0.019 \\
& 508 & 0.72 & 2.4 & 0.105 & 0.030 \\
9.8 & 493 & 0.56 & 4.0 & 0.060 & 0.045 \\
& 508 & 0.57 & 4.7 & 0.121 & 0.073 \\
8.6 & 493 & 0.43 & 4.7 & 0.070 & 0.074 \\
& 508 & 0.40 & 5.6 & 0.142 & 0.122 \\
7.9 & 493 & 0.31 & 5.2 & 0.081 & 0.111 \\
& 508 & 0.31 & 6.2 & 0.156 & 0.186 \\
4.8 & 493 & 0.55 & 3.6 & 0.085 & 0.155 \\
& 508 & 0.55 & 4.3 & 0.162 & 0.255 \\
\hline
\end{tabular}

Reaction conditions: EtOH/Acid $=5 / 1,60^{\circ} \mathrm{C}$.

Experimental conditions and FTS activities are listed in Table 6. FTS reaction rates were calculated from Eq. (12), using the size-dependent parameters in Tables 1 and 5, and the experimental conditions in Table 6 (partial pressures of $\mathrm{H}_{2}, \mathrm{CO}$, and $\mathrm{H}_{2} \mathrm{O}$ ). Fig. 6 compares the calculated and experimental FTS reaction rates. The FTS results calculated using Eq. (12) from the size-dependent parameters (Tables 4 and 5) were not consistent with the experimental FTS results, and instead showed an opposing trend. Fig. 5 and Table 5 show that the calculated $k_{\text {FTS }}$ and $b$ values did not agree with the experimental results, and thus needed revision. $k$ FTs was recalculated using Eq. (7), assuming that $\chi$ depended on particle size. The catalyst surface

Table 5

\begin{tabular}{|c|c|c|c|c|c|c|c|}
\hline$\overline{d_{\text {cat }}(\mathrm{nm})}$ & $T(\mathrm{~K})$ & $k_{\mathrm{FTS}}\left(\mathrm{mol} \cdot \mathrm{g}_{\mathrm{cat}}{ }^{-1} \cdot \mathrm{h}^{-1} \cdot \mathrm{bar}^{-3 / 2}\right)$ & $b\left(\mathrm{bar}^{-2}\right)$ & $E_{\mathrm{a}}(\mathrm{kJ} / \mathrm{mol})$ & $-\Delta H(\mathrm{~kJ} / \mathrm{mol})$ & $E_{\text {aо }}(\mathrm{kJ} / \mathrm{mol})$ & $-\Delta H_{\infty}(\mathrm{kJ} / \mathrm{mol})$ \\
\hline \multirow[t]{2}{*}{12.4} & 493 & 0.058 & 0.033 & \multirow{2}{*}{101} & \multirow{2}{*}{64} & \multirow{10}{*}{102} & \multirow{10}{*}{60} \\
\hline & 508 & 0.115 & 0.054 & & & & \\
\hline \multirow[t]{2}{*}{9.8} & 493 & 0.062 & 0.045 & \multirow{2}{*}{100} & \multirow{2}{*}{66} & & \\
\hline & 508 & 0.125 & 0.073 & & & & \\
\hline \multirow[t]{2}{*}{8.6} & 493 & 0.066 & 0.055 & \multirow{2}{*}{99} & \multirow{2}{*}{67} & & \\
\hline & 508 & 0.131 & 0.090 & & & & \\
\hline \multirow[t]{2}{*}{7.9} & 493 & 0.068 & 0.830 & \multirow{2}{*}{98} & \multirow{2}{*}{68} & & \\
\hline & 508 & 0.135 & 0.105 & & & & \\
\hline \multirow[t]{2}{*}{4.8} & 493 & 0.091 & 0.198 & \multirow{2}{*}{97} & \multirow{2}{*}{71} & & \\
\hline & 508 & 0.720 & 0.341 & & & & \\
\hline
\end{tabular}

Rate constants $(k)$, adsorption parameters $(b)$, activation energies $\left(E_{\mathrm{a}}\right)$ and adsorption enthalpies $\left(\Delta H_{\infty}\right)$ for Co catalysts at 493 and $508 \mathrm{~K}$, calculated using Eqs. (6), (7), (10) and (11). 

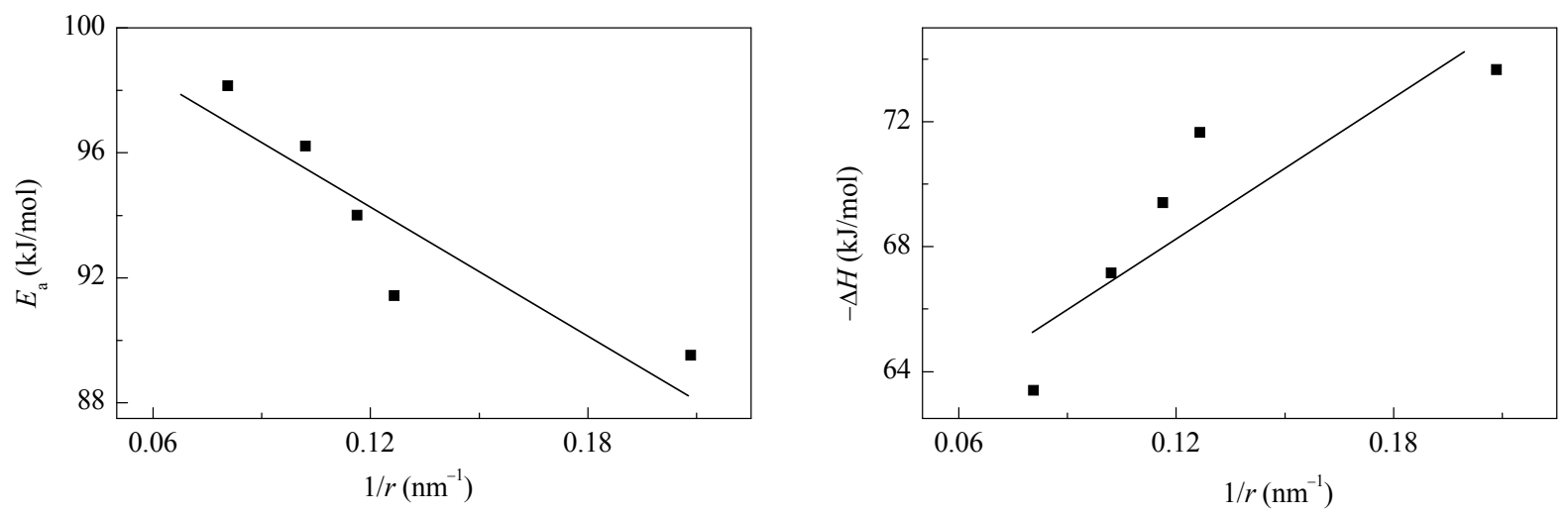

Fig. 5. Size-dependent activation energies and size-dependent adsorption enthalpies verses $1 / r$.
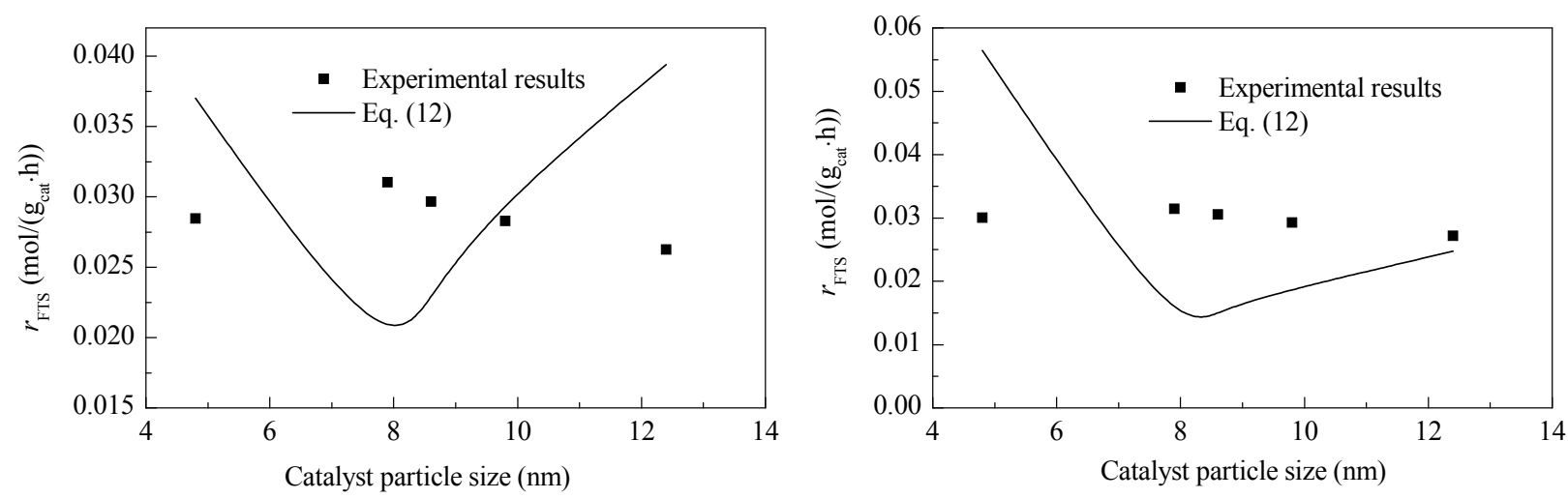

Fig. 6. Comparison of FTS reaction rates calculated using Eq. (12) with experimental results.

occupation was also assumed to depend on particle size. Thus, the number (4) in Eq. (6) was not an exact value, and depended on catalyst particle size. Thus, Eq. (6) can be rewritten as:

$$
b=b_{\infty} \exp \left(\frac{a \eta}{r}\right)
$$

In Eq. (13), $a$ is a parameter used to fit the experimental results. Table 7 lists the new size-dependent kinetic parameters, and results calculated using Eq. (12) with the new parameters. Fig. 7 shows that the calculated results are consistent with the experimental data. These results showed that a change in Co particle size changed the surface saturation of the catalyst.

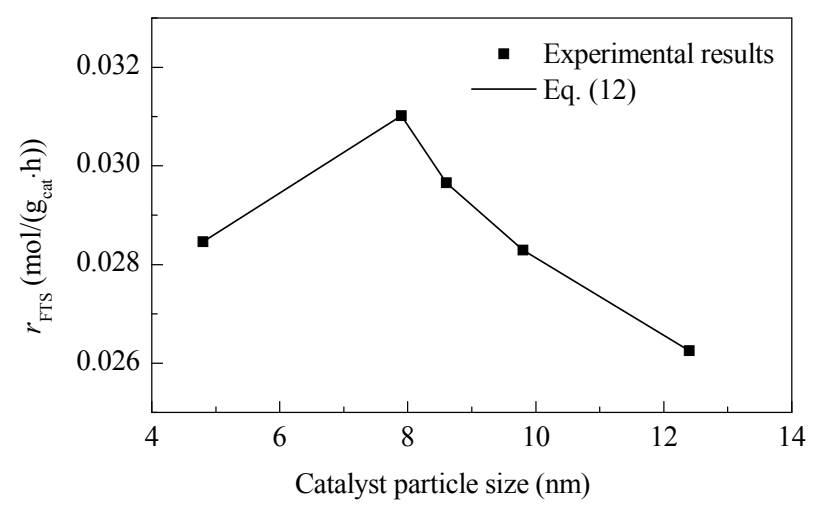

\section{Conclusions}

The influence of Co particle size on the FTS activity of CNT-supported catalysts was investigated. The microemulsion and impregnation methods were used to prepare catalysts with different Co particle sizes. Kinetic studies were performed to understand the effect of particle size on FTS activity. The size-dependent $k_{\infty}$ and size-independent $b_{\infty}$ increased, and the $\eta$ parameter decreased, with increasing reaction temperature. In recalculating the $k_{\mathrm{FTs}}$, the Polani parameter $\chi$ was assumed to

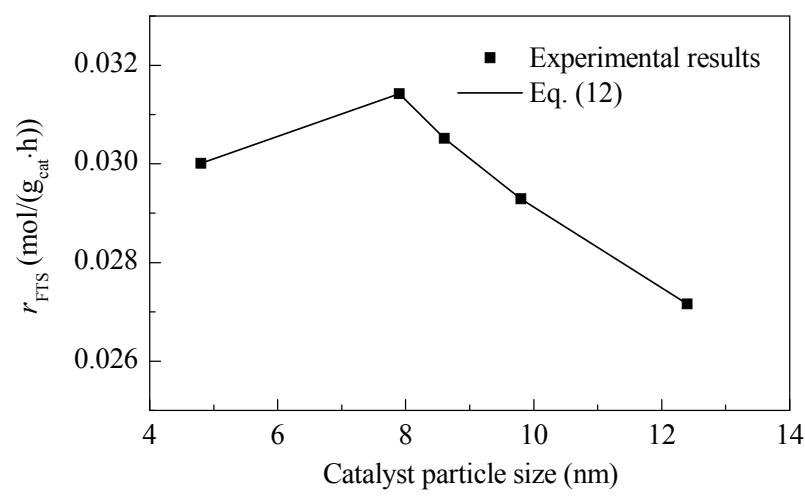

Fig. 7. Comparison of FTS reaction rates calculated from the new parameters in Table 7 using Eq. (12) with experimental results. 


\section{Graphical Abstract}

Chin. J. Catal., 2015, 36: 1372-1378 doi: 10.1016/S1872-2067(15)60840-3

\section{Particle size effects in Fischer-Tropsch synthesis by Co catalyst supported on carbon nanotubes}

Ali Nakhaei Pour*, Elham Hosaini, Mohammad Izadyar, Mohammad Reza Housaindokht

Ferdowsi University of Mashhad, Iran

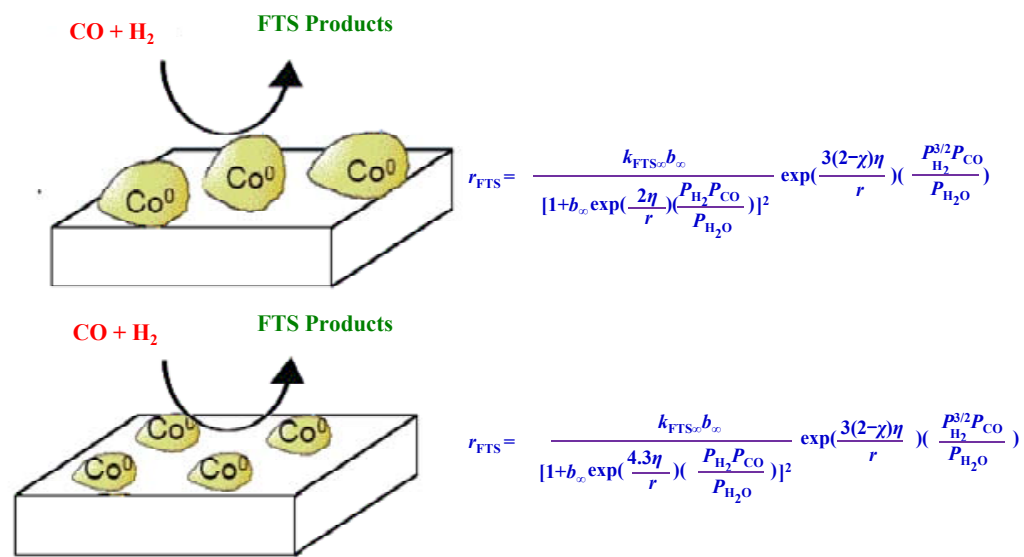

The effect of Co particle size on the Fischer-Tropsch synthesis activity of carbon nanotube-supported Co catalysts was investigated by kinetic studies.

depend on catalyst particle size. The surface occupation of the catalysts was assumed to also depend on catalyst particle size. The value of 4 in the equation of $b=b_{\infty} \exp \left(\frac{4 \eta}{r}\right)$ was therefore not exact, and so also depended on catalyst particle size.

\section{References}

[1] Bartholomew C H. Stud Surf Sci Catal, 1991, 64: 158

[2] Borg Ø, Dietzel P D C, Spjelkavik A I, Tveten E Z, Walmsley J C, Diplas S, Eri S, Holmen A, Rytte E. J Catal, 2008, 259: 161

[3] Borg Ø, Eri S, Blekkan E A, Storsæter S, Wigum H, Rytter E, Holmen A. J Catal, 2007, 248: 89

[4] Nakhaei Pour A, Housaindokht M R, Behroozsarand A, Khodagholi M A. Appl Phys A, 2014, 116: 789

[5] Nakhaei Pour A, Housaindokht M R, Torabi F, J Iran Chem Soc, 2014, 11: 1639

[6] Pei Y, Ding Y, Zhu H, Du H. Chin J Catal (裴彦鹏, 丁云杰, 朱何俊, 杜虹. 催化学报), 2015, 36: 355

[7] Borg Ø, Frøseth V, Storster S, Rytter E, Holmen A. Stud Surf Sci Catal, 2007, 167: 117

[8] den Breejen J P, Sietsma J R A, Friedrich H, Bitter J H, de Jong K P. J Catal, 2010, 270: 146

[9] Richard L A, Moreau P, Rugmini S, Daly F. Appl Catal A, 2013, 464 200

[10] Tavasoli A, Sadagiani K, Khorashe F, Seifkordi A A, Rohani A A, Nakhaeipour A. Fuel Processing Technol, 2008, 89: 491

[11] Nakhaei Pour A, Housaindokht M. Catal Lett, 2013, 143:1328

[12] Trépanier M, Dalai A K, Abatzoglou N. Appl Catal A, 2010, 374: 79

[13] Bezemer G L, Bitter J H, Kuipers H P C E, Oosterbeek H, Holewijn J E, Xu X, Kapteijn F, van Dillen A J, de Jong K P. J Am Chem Soc, 2006, 128: 3956
[14] Barbier A, Tuel A, Arcon I, Kodre A, Martin G A. J Catal, 2001, 200: 106

[15] Bezemer G L, Remans T J, van Bavel A P, Dugulan A I. J Am Chem Soc, 2010, 132: 8540

[16] Khodakov A Y. Catal Today, 2009, 144: 251

[17] Prieto G, Martínez A, Concepción P, Moreno-Tost R. J Catal, 2009, 266: 129

[18] Wang Z J, Skiles S, Yang F, Yan Z, Goodman D W. Catal Today, 2012, 181: 75

[19] Parmon V N. Doklady Phy Chem, 2007, 413: 42

[20] Murzin D Y. React Kinet Catal Lett, 2009, 97: 165

[21] Murzin D Y. Chem Eng Sci, 2009, 64: 1046

[22] Murzin D Y. J Catal, 2010, 276: 85

[23] Murzin D Y, Simakova I L. Kinet Catal, 2010, 51: 828

[24] Nakhaei Pour A, Housaindokht M R, Irani M, Kamali Shahri S M. Fuel, 2014, 116: 787

[25] Mart国ez A, López C, Márquez F, D承 I. J Catal, 2003, 220: 486

[26] Nakhaei Pour A, Housaindokht M R, Zarkesh J, Irani M, Babakhani E G. J Ind Eng Chem, 2012, 18: 597

[27] Nakhaei Pour A, Housaindokht M R. J Nat Gas Sci Eng, 2013, 14: 204

[28] Nakhaei Pour A, Housaindokht M R. J Nat Gas Sci Eng, 2013, 14: 29

[29] Nakhaei Pour A, Housaindokht M R. J Nat Gas Sci Eng, 2013,14: 49

[30] van Steen E, Schulz H. Appl Catal A, 1999,186: 309

[31] Nakhaei Pour A, Hosaini E, Tavasoli A, Behroozsarand A, Dolati F.J Nat Gas Sci Eng, 2014, 21: 772

[32] Chen L F, Song W L, Zhang Y H, Yang W M, Wu L H, Tang Y. Chin J Catal (陈立峰, 宋卫林, 张亚红, 杨为民, 吴良华, 唐臨. 催化学 报), 2014, 35: 1661

[33] Li X F, Bai F H, Su H Q. Chin J Catal (李雪芬, 白风华, 苏海全. 催化 学报), 2014, 35: 342

[34] Murzin D Y.J Mol Catal A, 2010, 315: 226 